\title{
Influence of Molybdenum on Tribo-Corrosion Behavior of 316L Stainless Steel in Artificial Saliva
}

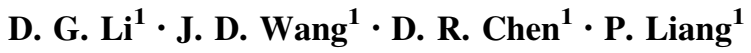

Received: 18 October 2014/Revised: 3 March 2015/Accepted: 19 March 2015/Published online: 8 April 2015

(c) Springer International Publishing AG 2015

\begin{abstract}
The influence of molybdenum on the tribocorrosion behavior of $316 \mathrm{~L}$ stainless steel in artificial saliva was investigated using potentiodynamic polarization curve, electrochemical impedance spectroscopy and sliding wear testing. The results showed that the passive capability of 316L stainless steel in artificial saliva was enhanced with increasing Mo. The anti-corrosion property of the passive film on $316 \mathrm{~L}$ stainless steel was improved with increasing Mo via increasing transfer resistance of the passive film. Sliding wear testing results showed that the friction coefficient of $316 \mathrm{~L}$ stainless steel in artificial saliva decreased with the increased Mo.
\end{abstract}

Keywords Artificial saliva $\cdot 316 \mathrm{~L}$ stainless steel · Molybdenum · Passive films · Friction coefficient

\section{Introduction}

Stainless steel, especially for 316L stainless steel, is widely used as orthopedic material owing to their superior corrosion resistance and good mechanical properties [1]. Corrosion resistance is an important factor that determines whether metallic bio-implant is biocompatible or not. High corrosion resistance of orthopedic material is required to reduce the release of metallic ions into the body and thus to improve its biocompatibility. In case of stainless steel, the corrosion resistance can vary depending on the grade of stainless steel used, where a compact passive film, mainly

D. G. Li

dgli@mail.tsinghua.edu.cn

1 State Key Laboratory of Tribology, Tsinghua University, Beijing 100084, China
$\mathrm{Cr}_{2} \mathrm{O}_{3}$, can automatically form on the surface of stainless steels in the existence of oxygen. This passive film is normally several nanometer thickness and highly defective [2-6]. Passive films existing between the substrate and the aggressive electrolyte can be deemed as the ions barrier to protect the substrate from further corrosion. Although stainless steels have extremely good general resistance, they are nevertheless susceptible to pitting corrosion in the environment containing chloride ions [7, 8]. However, saliva or body fluid may contain chloride ions, and then it is a potential threaten for orthopedic materials using stainless steel. Also, some food may be strong acidic and contain much chloride ions with frequent alternate cooling and heating. Therefore, improving the pitting corrosion resistance is very necessary for stainless steel in such a complex environment.

Excepting the electrochemical corrosion of orthopedic material in the oral cavity, the friction behavior of orthopedic material is also an important parameter. Therefore, the erosion corrosion interactions for orthopedic materials are important for the application of orthopedic materials. How to enhance the erosion-corrosion behavior of $316 \mathrm{~L}$ stainless steel in the oral cavity is vital to make them a suitable orthopedic material. Despite some papers have focused on the tribology behavior or erosion-corrosion property of stainless steel in the artificial saliva [9-11], systematic studies on the effect of molybdenum on the erosion-corrosion behavior of $316 \mathrm{~L}$ stainless steel in the artificial saliva are scarce.

Molybdenum is an important alloy element, which is widely used in metallurgy. The beneficial effect of Mo on the corrosion resistance of stainless steel has been attributed to several factors, such as the enrichment of $\mathrm{Cr}$ and Mo in the oxide layer [12-17], stabilization the passive film [18], thickening of the passive film [19], by synergistic 
interaction of Mo ions with other oxides of the passive film [20, 21], and by elimination of the active surface sites through formation of Mo oxides [22].

The aim of this work is to study the influence of Mo on the erosion-corrosion behaviors of $316 \mathrm{~L}$ stainless steel as an orthodontic material in artificial saliva using a microabrasion-corrosion apparatus. The electrochemical working station (M273A) is used to in situ record the electrochemical performance of 316L SS during fretting wear in the artificial saliva.

\section{Experimental}

\subsection{Sample Preparation}

The samples are prepared by melting the mixture of pure $\mathrm{Ni}$ (99.9 wt\%), pure $\mathrm{Cr}$ (99.9 wt\%), pure Fe (99.9 wt\%), pure Si (99.9 wt\%), pure Mo (99.9 wt\%), and pure carbon (99 $\mathrm{wt} \%$ ) in a vacuum electric furnace according to the proportion of each element contained in $316 \mathrm{~L}$ stainless steel except Mo element. The molten temperature is maintained at $1923 \mathrm{~K}$, after adequate stirring for $30 \mathrm{~min}$. When the molten temperature drops to $1723 \mathrm{~K}$, the molten alloy is poured into a copper mould with water cooling in the electric furnace to form the blank rod (Ф200×300 $\mathrm{mm}^{2}$ ), then, the rode is homogenized for $120 \mathrm{~min}$ at $1523 \mathrm{~K}$, hot rolling into 5-mm-thick plate. Finally, the thick plate is solution annealed at $1323 \mathrm{~K}$ for $60 \mathrm{~min}$, air cooling. The samples are prepared by manufacturing the thick plate into a size of $\Phi 10 \times 5 \mathrm{~mm}^{2}$. The compositions of the samples, determined by chemical analysis, are listed in Table 1. One round surface of the sample is abraded with a series of grits up to 5000 grit $\mathrm{SiC}$ paper, polished with 0.5 um $\mathrm{Al}_{2} \mathrm{O}_{3}$ powder and then cleaned using double-distilled water.

\subsection{Micro-abrasion-Corrosion Test}

The erosion-corrosion tests are carried out at UMT2 friction and wear testing machine. One round surface of the sample exposed to the electrolyte acts as the working surface with the applied load, and other surfaces are sealed by epoxy resin in the fixture. The schematic of erosioncorrosion test is list in Fig. 1, in which the loads are 1, 2, 3 and $4 \mathrm{~N}$, respectively. The friction pair is ceramic globule

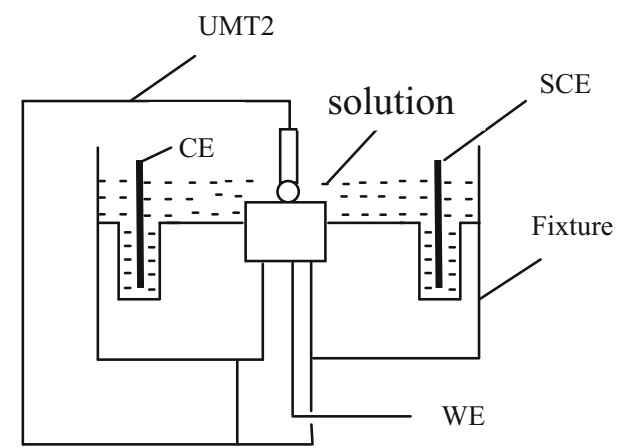

Fig. 1 Schematic of tribo-corrosion test

with the diameter of $3 \mathrm{~mm}$, and the moving frequency of ceramic globule is $20 \mathrm{~Hz}$, and the moving distance is $3 \mathrm{~mm}$. The abrasive slurry is the artificial saliva with the $\mathrm{pH}$ value of 5.7, and Table 2 [23] shows the chemical composition of the artificial saliva.

Nanoindentation tests are performed using a UMIS-2000 indentation system. A "loading-partial unloading" scheme is employed using a Berkovich indenter. In this loading scheme, the load was increased to a maximum of $20 \mathrm{mN}$ in 20 steps. The load is held at each incremental step for $0.1 \mathrm{~s}$ and then partially unload after each loading step.

SEM images are conducted using a LEO 1550 SEM with a Schottky field emitter source at $5 \mathrm{kV}$ accelerating voltage, using a $30 \mu \mathrm{m}$ aperture, at a working distance of 3-6 mm.

All of the experiments are performed on an EG\&G Model 273A potentiostat/galvanostat with an M5210 lockin amplifier. During the electrochemical experiments, the sliding wear testing is carried out simultaneously. All electrochemical experiments, a conventional three-electrode system is used, and the counter electrode is a Pt wire. All of the potentials are measured against a saturated calomel electrode (SCE).

Potentiodynamic curves are measured ranging from $-0.25 \mathrm{~V}_{\mathrm{OCP}}$ to $1.2 \mathrm{~V}_{\mathrm{SCE}}$ at a scan rate of $1 \mathrm{mV} / \mathrm{s}$.

EIS measurements are performed at the corrosion potential $\left(E_{\text {corr }}\right)$, the sweep frequency ranging from $10 \mathrm{kHz}$ to $5 \mathrm{mHz}$ with a potential amplitude of $10 \mathrm{mV}$. The experimental data are analyzed using the ZSimpWin software.

All the electrochemical experiments and sliding wear testing are performed at $25^{\circ} \mathrm{C}$.
Table 1 The chemical compositions of $316 \mathrm{~L} \mathrm{SS}$ containing Mo (wt\%)

\begin{tabular}{llllllllll}
\hline Sample & $\mathrm{C}$ & $\mathrm{S}$ & $\mathrm{P}$ & $\mathrm{Si}$ & $\mathrm{Mn}$ & $\mathrm{Mo}$ & $\mathrm{Ni}$ & $\mathrm{Cr}$ & $\mathrm{Fe}$ \\
\hline $1 \#$ & 0.018 & 0.013 & 0.027 & 0.78 & 1.49 & 2.5 & 11.97 & 16.97 & 66.232 \\
$2 \#$ & 0.019 & 0.014 & 0.028 & 0.77 & 1.50 & 3.96 & 11.98 & 16.98 & 64.749 \\
$3 \#$ & 0.018 & 0.015 & 0.029 & 0.81 & 1.47 & 5.97 & 11.97 & 16.97 & 62.748 \\
$4 \#$ & 0.018 & 0.013 & 0.030 & 0.78 & 1.48 & 7.99 & 11.95 & 16.96 & 60.50 \\
\hline
\end{tabular}


Table 2 The artificial saliva composition (g/l)

\begin{tabular}{lllllll}
\hline $\mathrm{NaCl}$ & $\mathrm{KCl}$ & $\mathrm{CaCl}_{2} \cdot 2 \mathrm{H}_{2} \mathrm{O}$ & $\mathrm{NaH}_{2} \mathrm{PO}_{4} \cdot 2 \mathrm{H}_{2} \mathrm{O}$ & $\mathrm{Na}_{2} \mathrm{~S} \cdot 9 \mathrm{H}_{2} \mathrm{O}$ & Urea & Distilled water \\
\hline 0.4 & 0.4 & 0.795 & 0.78 & 0.005 & 1 & 1000 \\
\hline
\end{tabular}
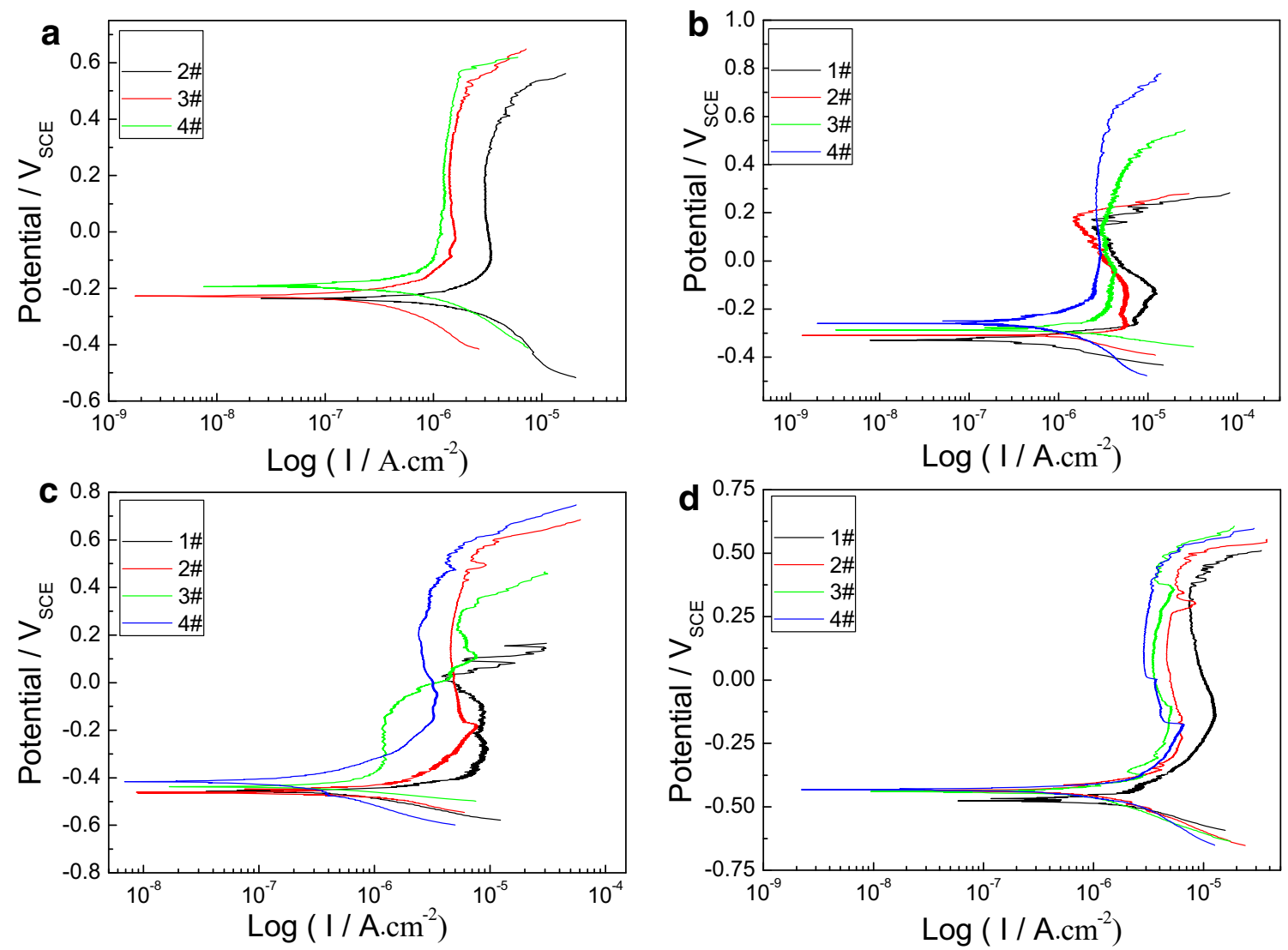

Fig. 2 Potentiodynamic polarization curves of 316L SS containing Mo under various loads in artificial saliva, a load of $1 \mathrm{~N}$, b load of $2 \mathrm{~N}$, $\mathbf{c}$ load of $3 \mathrm{~N}$ and $\mathbf{d}$ load of $4 \mathrm{~N}$

\section{Results and Discussions}

\subsection{Potentiodynamic Polarization Curves}

The potentiodynamic polarization curves of $316 \mathrm{~L}$ stainless steel containing Mo in artificial saliva with various loads are depicted in Fig. 2. It is evident that all tested samples are spontaneously passivated, as indicated by the absence of active/passive transient peaks in all curves. Figure 2a shows that the corrosion potential $\left(E_{\text {corr }}\right)$ of $316 \mathrm{~L}$ stainless steel containing $3.96 \mathrm{wt} \%$ Mo in the artificial saliva with a $1 \mathrm{~N}$ load is $-0.24 \mathrm{~V}_{\mathrm{SCE}}$. The sample is in the steady passive state in the potential region from -0.09 to $0.26 \mathrm{~V}_{\mathrm{SCE}}$ with the corresponded steady passive current density of $2.97 \times 10^{-6} \mathrm{~A} \mathrm{~cm}^{-2}$. Evidently, the corrosion potential moves to the positive direction, the steady passive potential region enlarges, and the steady passive current density decreases with increasing Mo, implying enhanced erosioncorrosion resistance of 316L stainless steel with Mo. The

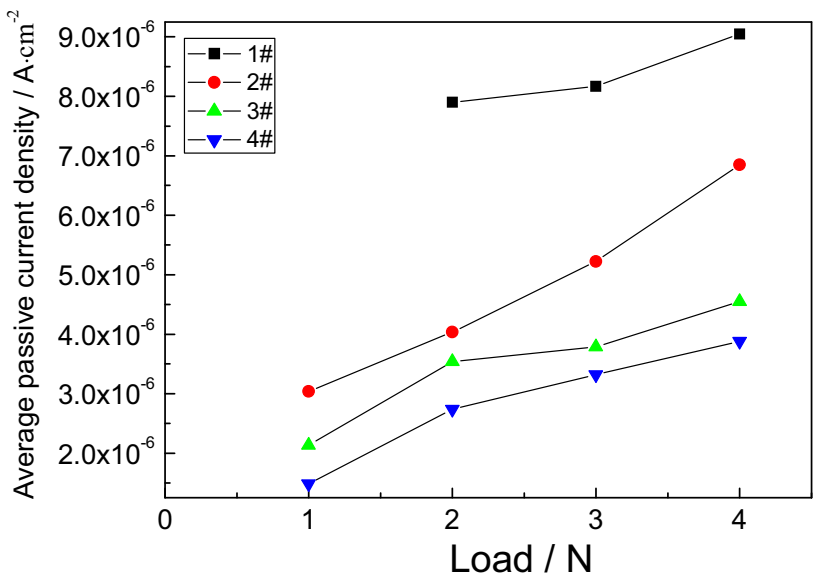

Fig. 3 Variations of average passive current density and load for four samples in artificial saliva

corrosion potential moves to the negative direction, the steady passive current density increases and the passive potential region decreases with increasing the applied load 

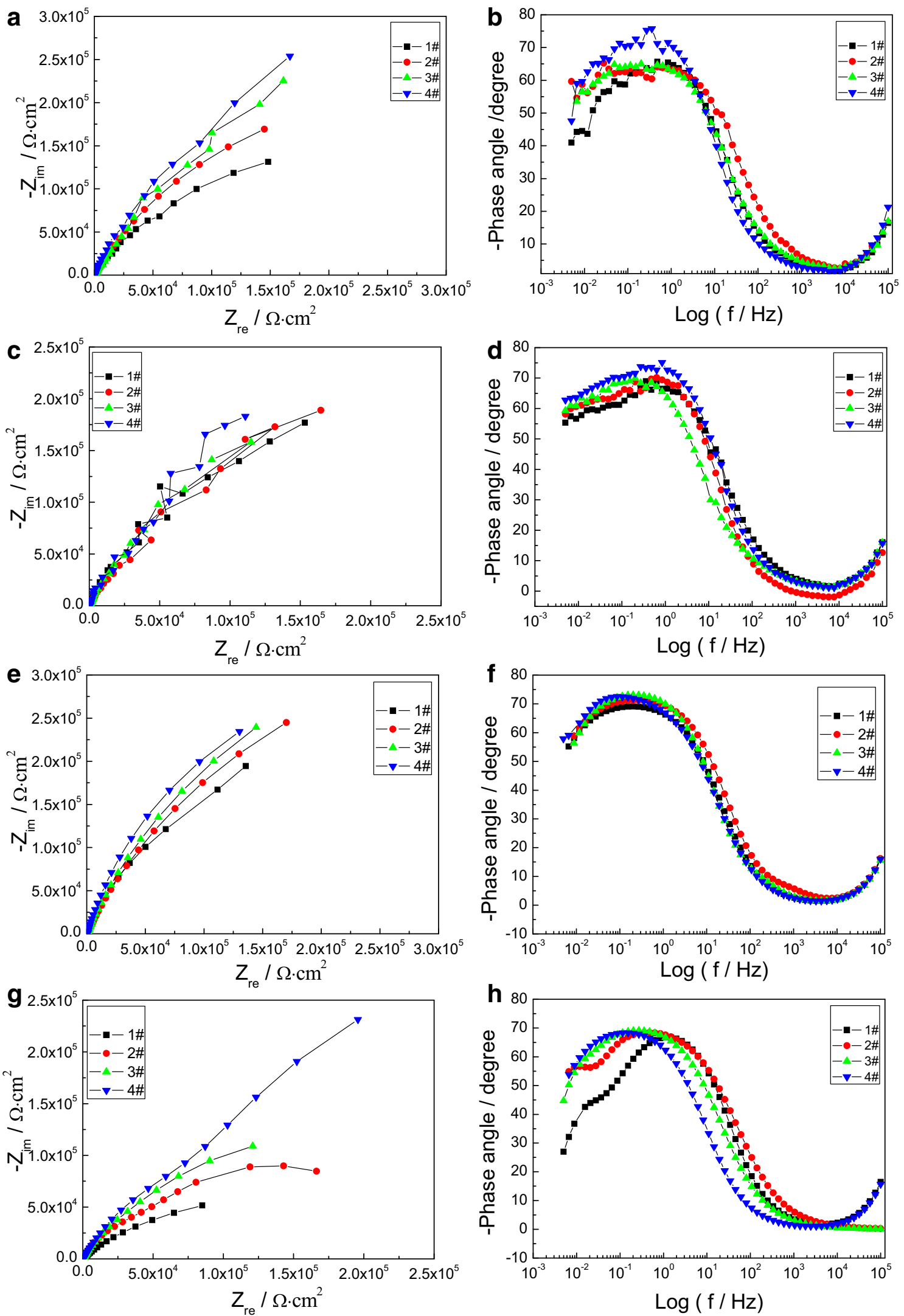

Fig. 4 Electrochemical impedance spectra of passive film on 316L SS containing Mo under various loads in artificial saliva, a and b load of $1 \mathrm{~N}$, c and $\mathbf{d}$ load of $2 \mathrm{~N}$, e and $\mathbf{f}$ load of $3 \mathrm{~N}, \mathbf{g}$ and $\mathbf{h}$ load of $4 \mathrm{~N}$ 
in case of every sample. In order to clarify the Mo effect on the erosion-corrosion behavior of 316L stainless steel in artificial saliva, Fig. 3 shows the variations of average passive current density and load for four samples, it can be seen that the average passive current density increases with increasing applied load in case of every sample. The average passive current density decreases with increasing Mo in case of one fixed applied load, it indicating the enhanced erosion-corrosion resistance of $316 \mathrm{~L}$ stainless steel with increasing Mo.

\subsection{Electrochemical Impedance Spectra of the Passive Films on 316L Stainless Steels Containing Mo}

To obtain the effect of Mo on the erosion-corrosion performance of $316 \mathrm{~L}$ stainless steel, Fig. 4 displays the Nyquist plots and the corresponded Bode diagrams of the passive films on 316 stainless steel containing Mo during wear process in artificial saliva. It is clear that all Nyquist plots show depressed capacitive arcs. The diameters of the semicircles and the corresponding phase angles increase with increasing Mo in case of one fixed applied load, suggesting that the addition of Mo greatly improving the erosion-corrosion resistance of $316 \mathrm{~L}$ stainless steel in artificial saliva. The capacitive arc shrinks and the corresponding phase angle decreases with increasing applied load in case of every sample, implying the decreased erosion-corrosion resistance.

In order to gain the quantitative explanation of Mo on the erosion-corrosion performance of 316L stainless steel in the artificial saliva, the measured EIS are fitted by appropriate equivalent electron circuit using ZsimpWin software. The equivalent electron circuit with three

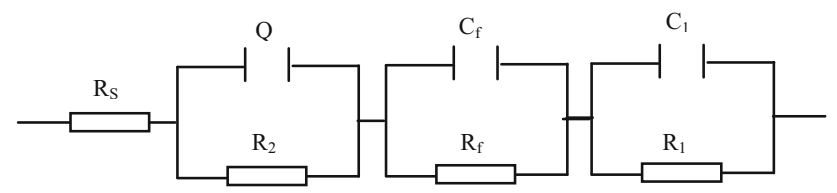

Fig. 5 Equivalent circuit $\left(R_{\mathrm{s}}-\left(R_{2} / / \mathrm{CPE}\right)-\left(R_{\mathrm{f}} / / C_{\mathrm{f}}\right)-\left(R_{1} / / C_{1}\right)\right)$ used for fitting the EIS spectra hierarchically distributed time constants provided by Macdonald [24] (shown in Fig. 5) is used to fit the impedance, in which $C_{1}$ and $R_{1}$ represent the capacitive and resistive contributions of the metal/film interface, $C_{\mathrm{f}}$ and $R_{\mathrm{f}}$ represent the capacitance and resistance of the bulk passive film, $R_{2}$ and CPE (constant phase element) represent the solution/barrier interface, and $R_{\mathrm{S}}$ is the solution resistance. The CPE has the properties of a capacitance when $0.5<n<1$. Frequency dispersion leading to CPE behavior can be attributed to geometry-induced nonuniform current $[25,26]$ and potential distribution (2D distribution) or to charge-discharge of oxide layers [27, 28] or to porosity or to surface roughness $[29,30]$ (3D distribution). For blocking electrode, the impedance of the CPE can be obtained with the following relationship [31, 32]:

$Z_{\mathrm{CPE}}=\left[Y_{0}(j w)^{\alpha}\right]^{-1}$,

$Y_{\mathrm{CPE}}=Y_{0}(j \omega)^{\alpha}$,

where $j$ is the imaginary number, and $w$ is the frequency of the alternating current. The exponent, $\alpha$, is defined as the CPE power, which is adjusted between 0 and 1 . For $\alpha=1$, the CPE describes an ideal capacitor with $Y_{0}$ equal to the capacitance C. For $\alpha=0$, the CPE is an ideal resistor. When $\alpha=0.5$, the CPE represents the Warburg impedance with diffusion character. The CPE has the properties of a capacitance when $0.5<\alpha<1$. The CPE describes the frequency dispersion of the time constants because of local

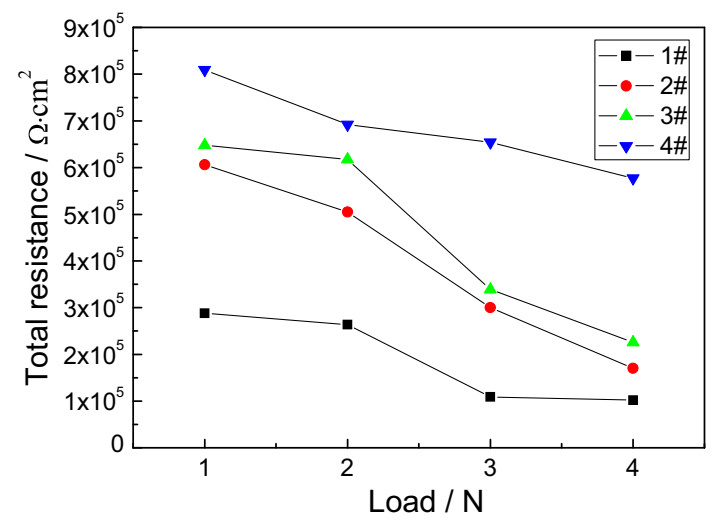

Fig. 6 Variations of total resistance and load in cases of four samples

Table 3 Fit parameters for equivalent circuits corresponding to EIS measurements of 316L stainless steel in artificial saliva during wear process with an applied load of $1 \mathrm{~N}$

\begin{tabular}{|c|c|c|c|c|c|c|c|c|c|c|}
\hline Samples & $R_{\mathrm{s}}\left(\Omega \mathrm{cm}^{2}\right)$ & $Q\left(\Omega^{-1} \mathrm{~s}^{\alpha}\right)$ & $\alpha$ & $R_{2}\left(\Omega \mathrm{cm}^{2}\right)$ & $C_{\mathrm{f}}\left(\mathrm{F} \mathrm{cm}^{-2}\right)$ & $R_{\mathrm{f}}\left(\Omega \mathrm{cm}^{2}\right)$ & $C_{1}\left(\mathrm{~F} \mathrm{~cm}^{-2}\right)$ & $\mathrm{R}_{1}\left(\Omega \mathrm{cm}^{2}\right)$ & $\Sigma R\left(\Omega \mathrm{cm}^{2}\right)$ & $\Sigma \chi^{2}$ \\
\hline $1 \#$ & 28.33 & $5.05 e-5$ & 0.75 & $2.85 \mathrm{e} 5$ & $1.45 \mathrm{e}-6$ & 422 & $3.61 \mathrm{e}-6$ & 33.65 & $2.88 \mathrm{e} 5$ & $4.53 e-4$ \\
\hline $2 \#$ & 25.55 & $4.73 e-5$ & 0.71 & $6.05 \mathrm{e} 5$ & $1.38 \mathrm{e}-6$ & 133.8 & $1.23 e-6$ & 32.18 & $6.06 \mathrm{e} 5$ & $1.87 \mathrm{e}-3$ \\
\hline $3 \#$ & 56.41 & $314 \mathrm{e}-5$ & 0.78 & $6.46 \mathrm{e} 5$ & $1.22 \mathrm{e}-6$ & 412 & $5.89 \mathrm{e}-6$ & 24.41 & $6.48 \mathrm{e} 5$ & $2.85 \mathrm{e}-3$ \\
\hline $4 \#$ & 11.82 & $247 e-5$ & 0.85 & $1.22 \mathrm{e} 5$ & $1.45-6$ & 410.9 & $1.51 \mathrm{e}-6$ & $6.81 \mathrm{e} 5$ & $8.09 \mathrm{e} 5$ & $1.33 \mathrm{e}-3$ \\
\hline
\end{tabular}


Fig. 7 SEM images of four specimens after wear with a load of $1 \mathrm{~N}$ and a freuquency of $20 \mathrm{~Hz}$

Fig. 8 Load verse displacement plots of four specimens, a 1\#; b 2\#; c 3\# and d 4\#
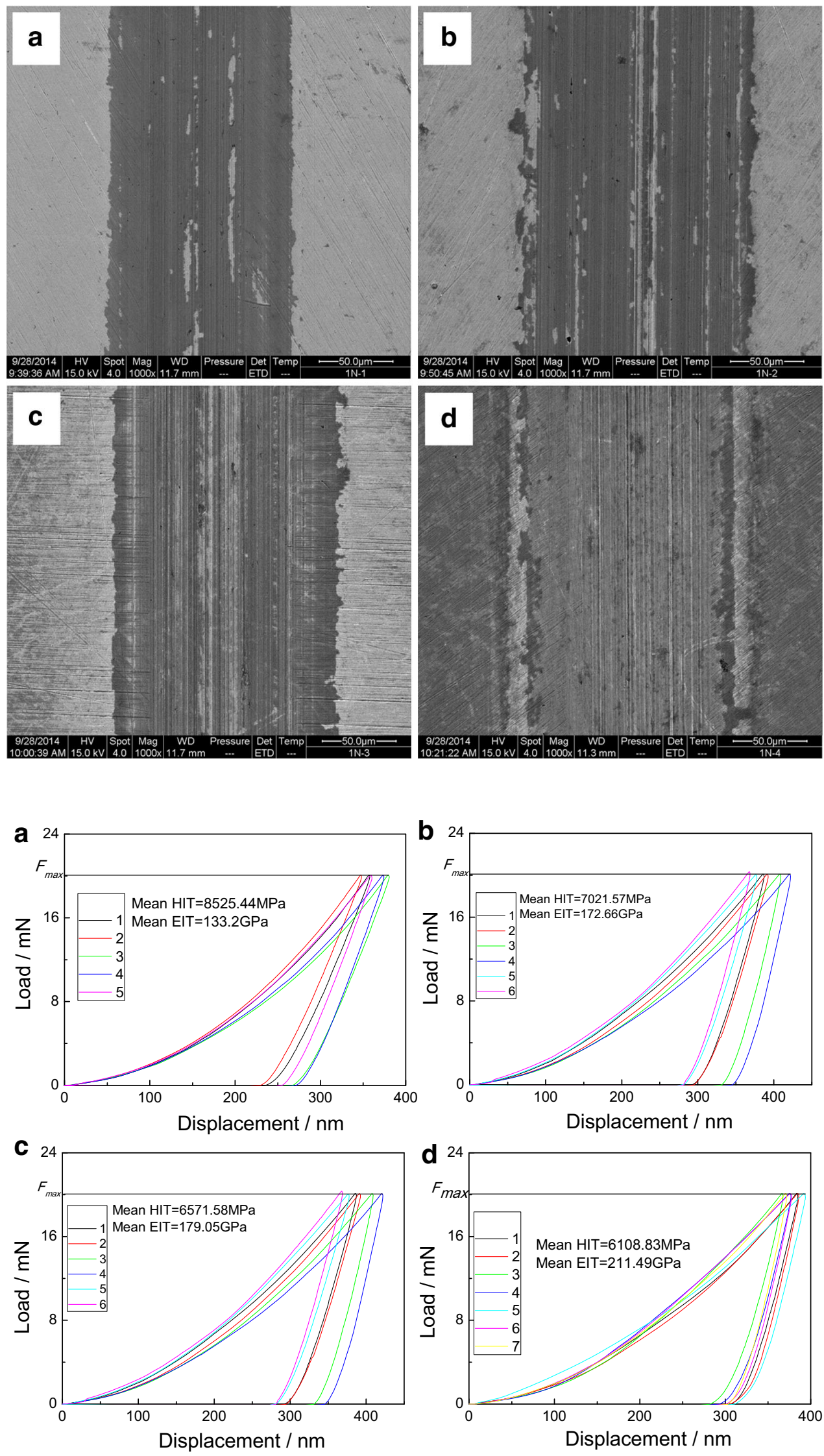
inhomogeneity [33-36], porosity and roughness of the electrode surface $[30,37]$.

Table 3 summarizes the fitting results, the Chi squared $\left(\chi^{2}\right)$ values of the order of $10^{-3}-10^{-4}$ indicating satisfactory agreement between the experimental and simulated data. The fitting results shows that the value of $\alpha$ is in the range of 0.71 and 0.85 for all the fitted results, validating the association of the CPE to a frequency disperse electrode. The total resistance $(\Sigma R)$ significantly increases with the increase Mo, while the values of $C_{1}, C_{\mathrm{f}}$ and $Q$ degrade,

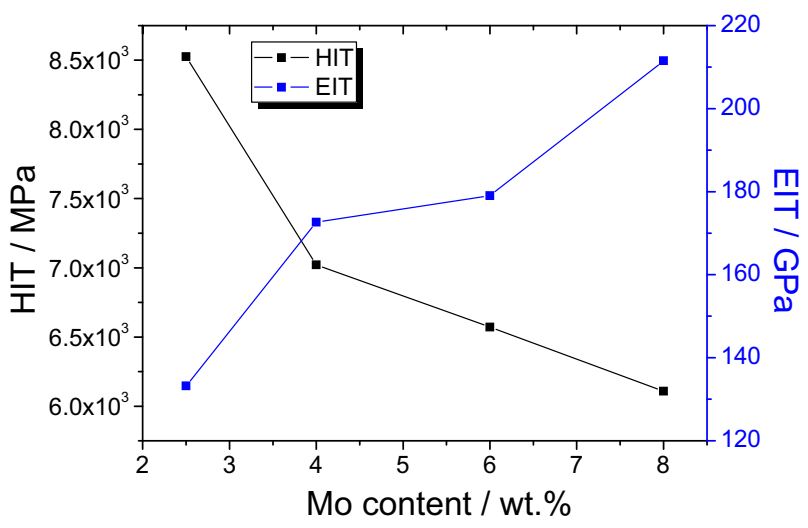

Fig. 9 Variations of HIT/EIT with Mo content
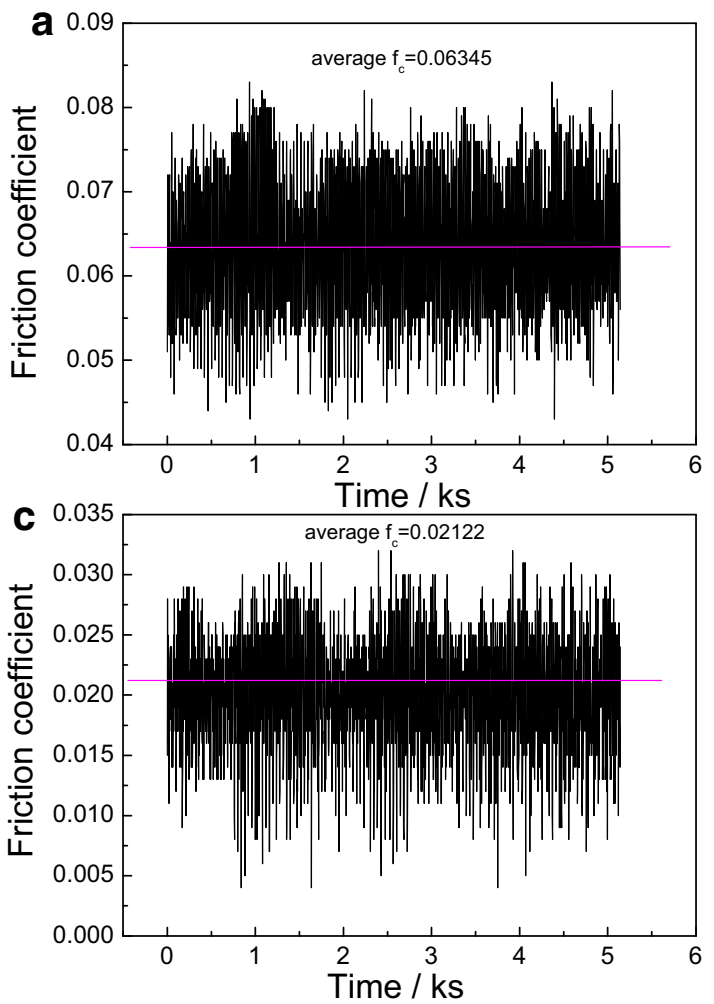

implying of the enhanced film protection with Mo. Figure 6 gives the variations of total resistance and load in cases of four samples in artificial saliva, it can be seen that the total resistance decreases with increasing load in case of every sample, and the total resistance increases with increasing Mo content in case of one fixed load.

\subsection{Influence of Mo on the Friction Coefficient of 316L Stainless Steels in Artificial Saliva}

As noted above, the dental implants and food particles or implants themselves may wear with each other excepting the electrochemical corrosion in the oral cavity, therefore, the wear characterization is vital to the dental implants. Figure 7 shows the SEM images of four specimens after wear with a load of $1 \mathrm{~N}$ and a frequency of $20 \mathrm{~Hz}$ in the artificial saliva. It can be seen that the scratch width increases with the increment of Mo content, the variation of scratch and Mo content may be related to the dependence of the mechanical properties of the substrate on Mo.

To obtain the effect of Mo on the mechanical strength, nanoidentation test is afforded. The typical load-displacement curves for specimens $1 \#, 2 \#, 3 \#$ and $4 \#$ with a maximum load of $20 \mathrm{mN}$ are showed in Fig. 8, the mean values of the reduced elastic modulus (EIT) and hardness (HIT) of four samples are automatically calculated by the
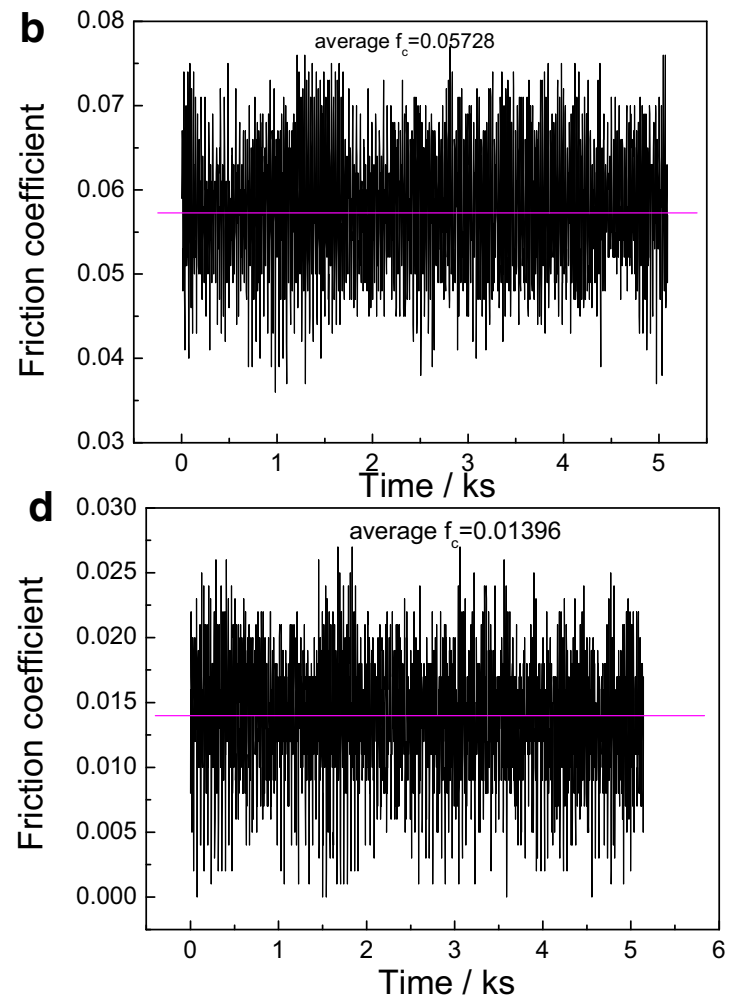

Fig. 10 Friction coefficient verse time plots of four specimens in artificial saliva with an applied load of $2 \mathrm{~N}$, a $1 \#$, b $2 \#$, c $3 \#$ and d $4 \#$ 
CSM indentation software. The variations of EIT and HIT with Mo concentration for four samples are depicted in Fig. 9, it can be seen that EIT increases from 133.2 to 211.49 GPa, and HIT decreases from 8525.44 to 6108.83 MPa corresponding to increasing Mo from 2.5 to $8 \%$, respectively. To insight into the Mo effect on the wear characterization of $316 \mathrm{~L}$ in the artificial saliva, Fig. 10 gives the friction coefficient verse time plots of four specimens in artificial saliva with an applied load of $2 \mathrm{~N}$. It apparently displays that the average friction coefficient decreases from 0.0635 to 0.01396 corresponding to increasing Mo from 2.5 to $8 \%$. Significantly, the Mo addition can sharply decrease the friction coefficient of $316 \mathrm{~L}$ $\mathrm{SS}$ in artificial saliva, which may be beneficial to the design of the dental implants. The influence of Mo on the wear characterization can be attributed to the variation of the mechanical property with Mo. As showed in Fig. 8, high HIT means the high wear resistance, and then the scratch width increases with the increased Mo. While Fig. 10 shows the friction coefficient decreases with the increased Mo, it may be related to the composition changing of the passive film on 316L SS.

\section{Conclusions}

The element Mo was added to 316L SS. The erosion-corrosion properties of $316 \mathrm{~L}$ stainless steel in artificial saliva were explored using potentiodynamic polarization curve, EIS and wear test. The following conclusions can be drawn:

1. 316L SS was in the passive state in artificial saliva, the passive current density decreases and the passive potential region increases with increased Mo.

2. Mo can increase the transfer resistance of the passive films on $316 \mathrm{~L}$ stainless steel by improving the compactness of the passive film and by increasing the charge resistances between the film/solution and substrate/film interfaces.

3. Mo can improve the elastic modulus (EIT) and decrease the hardness (HIT) of 316L stainless steel. The friction coefficient of 316L SS in artificial saliva decreases with increasing Mo.

Acknowledgments This work is financially supported by the National Nature Science Foundation of China (No. 51305228).

\section{References}

1. Sharifnabi A, Fathi MH, Eftekhari Yekta B, Hossainalipour M (2014) The structural and bio-corrosion barrier performance of Mg-substituted fluorapatite coating on 316L stainless steel human body implant. Appl Surf Sci 288:331-340
2. Turnbull A, Ryan M, Willetts A, Zhou SQ (2003) Corrosion and electrochemical behaviour of 316L stainless steel in acetic acid solutions. Corros Sci 45:1051-1072

3. Kuczynska-Wydorska M, Flis J (2008) Corrosion and passivation of low-temperature nitrided AISI 304L and 316 stainless steels in acidified sodium sulphate solution. Corros Sci 50:523-533

4. Fujimoto S, Shibata T, Wada K, Tsutae T (1993) The electrochemical conditions for coloured film formation on type 304 stainless steel with square wave polarization. Corros Sci 35:147-152

5. Conrrado R, Bocchi N, Rocha-Filho RC, Biaggio SR (2003) Corrosion resistance of colored films grown on stainless steel by the alternating potential pulse method. Electrochim Acta 48:2417-2424

6. Babic R, Metikos-Hukovic M (1993) Semiconducting properties of passive films on AISI 304 and 316 stainless steels. J Electroanal Chem 358:143-160

7. Williams DE, Westcott C, Fleischmann M (1985) Select this articleStochastic models of pitting corrosion of stainless steels: I. modeling of the initiation and growth of pits at constant potential. J Electrochem Soc 132:1796-1804

8. Eklund GS (1974) Initiation of pitting at sulfide inclusions in stainless steel. J Electrochem Soc 121:467-473

9. Kosukegawa H, Fridrici V, Laurenceau E, Kapsa P, Ohta M (2015) Friction of 316 L stainless steel on soft-tissue-like poly(vinyl alcohol) hydrogel in physiological liquid. Tribol Int 82:407-414

10. Raadnui S, Mahathanabodee S, Tongsri R (2008) Tribological behaviour of sintered 316L stainless steel impregnated with $\mathrm{MoS}_{2}$ plain bearing. Wear 265:546-553

11. Henry P, Takadoum J, Bercot P (2009) Tribocorrosion of $316 \mathrm{~L}$ stainless steel and TA6V4 alloy in $\mathrm{H}_{2} \mathrm{SO}_{4}$ media. Corros Sci 51:1308-1314

12. Tan MW, Akiyama E, Kawashima A, Asami K, Hashimoto K (1995) The effect of air exposure on the corrosion behavior of amorphous Fe-8Cr-Mo-13P-7C alloys in $1 \mathrm{M} \mathrm{HCl}$. Corros Sci 37:1289-1301

13. Habazaki H, Kawashima A, Asami K, Hashimoto K (1992) The corrosion behavior of amorphous Fe-Cr-Mo-P-C and Fe-Cr-W-P$\mathrm{C}$ alloys in $6 \mathrm{M} \mathrm{HCl}$ solution. Corros Sci 33:225-236

14. Abreu CM, Cristóbal MJ, Losada R, Nóvoa XR, Pena G, Pérez MC (2004) Comparative study of passive films of different stainless steels developed on alkaline medium. Electrochim Acta 49:3049-3056

15. Montemor MF, Simões A, Ferreira MGS, Da Cunha M (1999) Belo, The role of Mo in the chemical composition and semiconductive behaviour of oxide films formed on stainless steels. Corros Sci 41:17-34

16. Lu YC, Clayton CR (1989) An XPS study of the passive and transpassive behavior of molybdenum in deaerated $0.1 \mathrm{M} \mathrm{HCl}$. Corros Sci 29:927-937

17. Vignal V, Olive JM, Desjardins D (1999) Effect of molybdenum on passivity of stainlesssteelsin chloride media using ex situ near fieldmicroscopyobservations. Corros Sci 41:869-884

18. Olefjord I, Brox B, Jelvestam U (1985) Surface composition of stainless steels during anodic dissolution and passivation studied by ESCA. J Electrochem Soc 132:2854-2861

19. Schultze JW, Lohrengel MM, Ross D (1993) Nucleation and growth of anodic oxide films. Electrochim Acta 28:973-984

20. Sugimoto K, Sawada Y (1977) The role of molybdenum additions to austenitic stainless steels in the inhibition of pitting in acid chloride solutions. Corros Sci 17:425-445

21. Akiyama E, Kawashima A, Asami K, Hashimoto K (1996) The effects of alloying elements on the passivity of sputter-deposited amorphous Al-Cr-Mo alloys in $1 \mathrm{M} \mathrm{HCl}$. Corros Sci 38:1281-1294 
22. Hashimoto K, Asami K, Teramoto K (1979) An X-ray photoelectron spectroscopic study on the role of molybdenum in increasing the corrosion resistance of ferritic stainless steels in HC1. Corros Sci 19:3-14

23. Holmes D, Sharifi S, Stack MM (2014) Tribo-corrosion of steel in artificial saliva. Tribol Int 75:80-86

24. Priyantha N, Jayaweera P, Macdonald DD, Sun A (2004) An electrochemical impedance study of Alloy 22 in $\mathrm{NaCl}$ brine at elevated temperature I. Corrosion behavior. J Electroanal Chem 572:409-419

25. Lukacs Z (1997) The numerical evaluation of the distortion of EIS data due to the distribution of parameters. J Electroanal Chem 432:79-83

26. Lukacs Z (1999) Evaluation of model and dispersion parameters and their effects on the formation of constant-phase elements in equivalent circuits. J Electroanal Chem 464:68-75

27. Young L (1961) Anodic oxide films. Academic Press, New York

28. Schiller CA, Strunz W (2001) The evaluation of experimental dielectric data of barrier coatings by means of different models. Electrochim Acta 46:3619-3625

29. Jurczakowski R, Hitz C, Lasia A (2004) Impedance of porous Au based electrodes. J Electroanal Chem 572:355-366
30. Pajkossy $T$ (2005) Impedance spectroscopy at interfaces of metals and aqueous solutions-Surface roughness, CPE and related issues. Solid State Ion 176:1997-2003

31. Juttner K (1990) Electrochemical impedance spectroscopy (EIS) of corrosion processes on inhomogeneous surfaces. Electrochim Acta 35:1501-1508

32. Alves VA, Brett Christopher MA (2002) Characterisation of passive films formed on mild steels in bicarbonate solution by EIS. Electrochim Acta 47:2081-2091

33. Lukacs Z (1997) The numerical evaluation of the distortion of EIS data due to the distribution of parameters. J Electroanal Chem 432:79-83

34. Lukacs Z (1999) Evaluation of model and dispersion parameters and their effects on the formation of constant-phase elements in equivalent circuits. J Electroanal Chem 464:68-75

35. Young L (1961) Anodic oxide films. Academic Press, New York

36. Schiller CA, Strunz W (2001) The evaluation of experimental dielectric data of barrier coatings by means of different models. Electrochim Acta 46:3619-3625

37. Jurczakowski R, Hitz C, Lasia A (2004) Impedance of porous Au based electrodes. J Electroanal Chem 572:355-366 